\title{
Exploring the Concept of School Mental Health Based on the Prosper Model
}

\section{Sigit Sanyata, Rita Eka Izzaty, and Nanang Erma Gunawan}

Faculty of Education, Yogyakarta State University

\section{Abstract}

This research aims to explore the empirical data on the concept of school mental health through the PROSPER model in Indonesian schools, particularly those in Yogyakarta Special Region. This is preliminary research of a larger study that aims to develop a guidebook for positive mental health in school setting. There are five schools in one municipality and four regencies ranging from elementary to high schools involved in this research. Students filled the modified PROSPER model instrument while the teachers and principals were interviewed based on the model's dimensions. The obtained data were analyzed descriptively, and the results showed that most students agreed that their schools had met all the principles or indicators of the PROSPER model. Both the

Corresponding Author: Sigit Sanyata

sanyatasigit@uny.ac.id

Received: 2 May 2019 Accepted: 19 June 2019 Published: 3 July 2019

Publishing services provided by Knowledge E

(c) Sigit Sanyata et al. This article is distributed under the terms of the Creative Commons

Attribution License, which permits unrestricted use and redistribution provided that the original author and source are credited.

Selection and Peer-review under the responsibility of the ICMEd Conference Committee.

\section{G OPEN ACCESS} teachers and principals have administered the school policies based on merits and values which are in line with the PROSPER model. Although some elements embrace the dimensions, it seems that the implementation still has some obstacles, particularly the lack of resources to support the mental health system at school. This result may be used to develop a guidebook on how to formulate the school-based mental health system that plays a role in improving the psychological wellbeing of the students.

Keywords: school mental health; PROSPER Model; positive mental health

\section{Introduction}

The study of mental health in Indonesian community has been progressively developing these years. It began since the mental health report published by the World Health Organization in [1]. Most research focus on epidemiology, assessment and primary care issues. However, research on the concept of mental health is still understudied.

Mental health is a state of emotional and psychological well-being in which an individual is able to use his or her cognitive and emotional capabilities, function in society, and meet the ordinary demands of everyday life [2]. Mental health involves not only the freedom from mental disorders, such as depression, anxiety, psychotic conditions, or personality problems, but also the regular experience of positive emotions, such as joy, wonder, happiness, resilience, satisfaction, meaning, purpose, and hope [3]; [4]. Mental Health is crucial to the overall well-being of individuals,societies and countries and must 
be universally regarded in a newlight [1]. It because mental health disorders contribute significantly to the global burden of non-communicable chronic disease [5].

Various research results show there are many factors that can affect a person's mental health condition, for example: good peer relationship, healthy school environment, nutrition and diet, religion, socio-demographic, mother's physical well-being, parentchild relationship, subjective financial well-being, one-parent household, lifestyle, organizational conditions (role conflict, role ambiguity, opportunities for professional development and social support), etc [6]; [7]; [2]; [8]; [9]; [10]; [11]; [12]; [13]; [3]; [14].

The statement implies that health, whether physical or mental wellbeing, is incredibly important to strengthen the quality future generation and produce highly-skilled human resources. The statement also emphasizes on how all elements of the nation must deliberately synergize and have a strong motivation to make an effort in developing the human resources and improving the nation's competitiveness. In regards to the government's strategic plan, this research attempts to raise the awareness by focusing on mental health issues. Mainly, this research is possible due to the more open perspectives of the mental health study, as the field no longer limits the discussion on the issues of mental illness and other psychological disorders alone, allowing the variable to be studied from other disciplines. In the multidisciplinary point of view, mental health issues are in fact closely related to other fields besides psychology and psychiatry, such as education.

Since the 2000's there have been an increase in the number of theoretical and empirical studies which find the relationship between health and the process and result of education [15]; [16]; [17]; [18]; [19]; [20]; [21]; [22]; [23]; [24]; [25]. In addition, many international organizations have shown numerous attempts to develop and improve the learning process and health in schools. World Health Organization, for example, launched their Health-Promoting Schools initiative; while UNICEF focused on human rights issues through programs such as the Child-Friendly Educational Systems and Schools, Education for All (EFA), Focusing Resources for Effective School Health (FRESH) [26].

The programs done by these world organizations emphasize the importance of education practices as the strategic setting to develop mental health-based programs which aim to improve the wellbeing of the school community including the teaching staff, the students, as well as the education personnel. Moreover, in addition to being the learning setting, school also provides a space for children and adolescents to spend most of their time as students, which in turn contribute to the development of their psychosocial and emotional skills [27]; [28]; [29]; [30]; [31]. On the other hand, 
many studies on psychological education, psychological development, psychological personality, and clinical psychology point out that learning settings play an important role in reducing the risks of unfavorable mental disorders during the development of children and adolescents.

\section{Literature Review}

\subsection{School based mental health}

A survey of Basic Health Research conducted in 2013 [32] shows that in Indonesia, the prevalence of severe mental disorders was 1.7 people per mile or as many as 1,728 people of all respondents. Yogyakarta Special Region and Aceh are the two provinces with the highest number of people with mental disorders (2.7\% respectively). Other provinces with considerable number of people with mental disorders are South Sulawesi, Bali, and Central Java. It is believed that the causes of severe mental disorders are due to the absence of immediate treatment and prevention when the early symptom of mental disorder was first spotted. In addition to severe mental disorders, $6 \%$ of Indonesian citizens (37.728 people out of all respondents) suffer emotional disorders. Central Sulawesi is the province with the highest prevalence of emotional disorders (11.6\%). It is followed by South Sulawesi (9.3\%), West Java (9.3\%), Yogyakarta Special Region (8.1\%), and East Nusa Tenggara (7.8\%). This trend in high prevalence of mental health problems will probably increase if necessary steps are not taken.

In psychology studies, positive psychology began to become a trusted trend to establish a good human quality because it helps to prosper of human beings in the face of adversity [33]. Studies on positive psychology have actually gone on for decades, long before Martin Seligman introduced positive psychology in 2000. Positive psychology departs from the concern that the positive psychiatric symptoms have not been intensively studied. In fact, it may be argued that the human psychological positive aspect is somewhat neglected. The traditional psychological view is more concerned with the mental disorder or mental illness and pathological aspects of human beings so that its usefulness is often limited to the curative actions of human psychological problems [34]; [35]; [26]; [36]; [33]; [37]. Thus, the goal of positive psychology is to provide conditions and processes that contribute to the optimal functioning of people, groups, and institutions [38].

Schools play a critical role in promoting well-being of children and adolescents [39]. When school has become a place to apply positive psychological view in countries such 
as the United States, European countries, and Australia; then the development of positive psychology has yielded new intervention models aiming at fostering mental health and promoting well-being in education [40]. As a role focus on material and cognitive aspects has shown weaknesses and threats to the humanitarian entity, education is slowly accommodating the positive psychological view in its practice. Some scholars believe that the school sector is a very strategic setting because of its role in human resource quality development [41]. By involving schools to improve the mental health of their students, the development of quality of life can be initiated, the prevention of minor to serious psychological problems can be prevented, addressed, and minimized.

The recognition that school plays an important role in improving mental health prompts the creation of various models of positive psychology application in educational settings. One of the models is the PERMA model which is developed based on Seligman's Authentic Happiness and Flourish (2011), the Huppert and So Model (2013), and the PROSPER framework [42]. Developing awareness is important to build a positive education system. Taking into account this fact, the PROSPER framework model is considered applicable so that it can include parts of the school system that have not been the subjects to positive educational practice. The PROSPER framework has several similarities to Seligman's (2011) earlier PERMA model of wellbeing (Positive emotions, Engagement, Relationships, Meaning and Accomplishment), but specifically includes two additional significant components: Strengths and Resilience [43]. In Indonesia, the study on the PROSPER model has not been carried out yet. Thus, empirical studies are needed to see how this model can be implemented in Indonesian systems and contexts.

This study aims at exploring both empirical data and theoretical analysis by testing the fitness of PROSPER Model as a school-based mental health system with Indonesian culture and social value. This research shows the empirical models and its compatibility with theoretical concepts and the concepts of mental health at schools. Furthermore, the research findings can be used as a reference to develop the concepts of policies written in a mental health guideline that is appropriate to be implemented at schools.

\subsection{PROSPER model}

The PROSPER model is a framework for implementing positive education into educational practices in the field. PROSPER is an acronym of seven key elements that contribute to happiness: positivity, relationship, outcomes, strength, purpose, engagement, and resilience [44]; [42]; [43]. These elements are further described as follows. 
Positivity. Positivity can be defined simply 'as the state of being positive' (Noble \& McGrath, 2015[46]). For students, positivity means experiencing positive emotions at school such as feeling secure, belonged, interested, happy, cheerful, and comfortable [42]. In addition, gratitude and appreciation as positive thoughts are included in the capacity for awareness and skill in optimistic thinking.

Relationship. In school, a focus on relationships means that school staff strategic steps to intentionally build positive relationships such as peer relationships, teacherstudent relationships, staff relationships and parent-school relationships [43]. In this aspect, it focuses on building positive and meaningful relationships to teach the prosocial values and social skills that enable the teachers to identify and implement schoolbased structures that facilitate the students [42].

Outcomes. Outcomes include progresses in goals, a feeling of being able to carry out schoolwork, understanding that achievement depends on hard work and effort, diligence, and growing mind, awareness to reach certain mastery and achievement [43]. When the student achieve an outcomes, it can contribute significantly to their sense of mastery, competence and accomplishment, a basic psychological need for wellbeing [45]. For teaching activities, the focus of this outcome is on attitudes and skills. Teachers use evidence-based teaching strategies that can facilitate school-based positive outcomes both academically and co-curricularly.

Strengths. A 'strength' has been defined as ways of behaving, thinking or feeling that an individual has a natural capacity for, enjoys doing and which allows the individual to achieve optimal functioning while they pursue valued outcomes [46]. Strengths include knowledge of self-characteristics, capabilities, and understanding of how to apply them in different contexts [42]. At school, there is an activity that really helps the students to recognize, develop, and find the best way to apply their strengths.

Purpose. Students have a sense of 'purpose' when they perceive that their goals are worthwhile [46]. In school context, purpose comprises believing what the students have learned as valuable and associating their feeling with someting bigger or wider than just themselves. Besides, focuses on services to school community members, to wider society members, and to the needs are also included [45].

Engagement. Engagement is a critical concept in education because it is a good predictor of academic outcomes [42]. This component refers to the psychological relationships of students with learning activities and with school, (e.g. enjoying learning, and staying connected, interested, and engaged in learning activities and in school life). In addition, there is also a focus on the effective strategies and evidence-based teaching 
to increase student engagement [42]. [47] and [48] have suggested that engagement can be behavioural, social, emotional and cognitive engagement.

Resilience. This includes not only having the capacity to revive after being down, making error, being in difficulties, and dare to face challenging situations; but also helpfull and rational thinking skills, adaptive distancing skills, using humour, optimistic thinking skills, and seeking assistance when needed [42]; [49]. Students who demonstrate resilience in the face of adversity perform better at school, experience greater wellbeing as compared to those who simply give up and are not resilient, under similar circumstances [50].

\section{Material \& Methodology}

This research uses a qualitative approach with exploratory research type, where this exploratory research is a preliminary research. The population of this study was all elementary schools located in Yogyakarta Special Region (DIY) spread in five regions (four regencies: Bantul, Gunung Kidul, Kulon Progo, and Sleman; and one municipality: the city of Yogyakarta). Based on the data from www.pendidikan-diy.go.id, the number of elementary schools in DIY reaches 2,001 units. The research respondents from each regency are listed as follows. (1) one person from the Department of Education and Culture, (2) one elementary school consisting of one teacher, one principal, and grades 3 and 5 students. The total subjects of the study as a whole were (1) 5 principals, 10 teachers (Grades 3 and 5), and about 350 students of the $3^{\text {rd }}$ and $5^{\text {th }}$ grades. In the meantime, the data collection for the elementary schools was only conducted in two regencies: Bantul and Kulon Progo. Bantul was represented by MI Al Muhsin I, while Kulon Progo was represented by State Elementary School (SD 3 Sentolo).

The data were collected from two primary schools, namely MI Al Muhsin I and SD N 3 Sentolo. The data were collected through (1) interviews with the school principal, in which each principal was given a set of open-ended questions related to how schools fostered positive feelings and characters, how schools taught students to recognize their potentials and interests, and how learning was done to foster students' critical and creative thinking; (2) a questionnaire administered to the $3^{r d}$ and $5^{\text {th }}$ graders, concerning the mental health concept of the school viewed from the students' perspectives, and it was divided into two sections: the first section consisting of 34 items, based on the PROSPER model, while the second one with 23 items based on the PERMA model; (3) interviews with the homeroom teachers of the $3^{\text {rd }}$ and $5^{\text {th }}$ grades, which used the 
instrument similar to the one used with the principals. The data that has been collected will be analyzed descriptively.

\section{Results and Discussion}

\subsection{Result}

Fifty-seven students of the $3^{r d}$ and $5^{\text {th }}$ grades of MI Al Muhsin (29 and 28 respectively) were involved as the research subjects, and were given the questionnaire. However, one student did not return the questionnaire and, thus, there were only 56 that could be analyzed. The data were analyzed using Microsoft Excel 2013 program. The finding shows that $90.13 \%$ and $96.64 \%$ students of MI Al Muhsin ( $3^{\text {rd }}$ and $5^{\text {th }}$ grades respectively) found that their school had implemented positive education practices that supported mental health at school based on the PROSPER model. On average, 93.38\% of MI Al Muhsin students agreed that their school had implemented positive education practices that promoted mental health at school. Meanwhile, based on the PERMA model, 78.46\% of the $3^{\text {rd }}$ grade students of Ml Al Muhsin perceived their school to have implemented positive education practices that supported mental health at school and $83.80 \%$ of the $5^{\text {th }}$ graders shared the same view. Thus, as many as $81.13 \%$ of MI Al Muhsin students stated that the school had performed positive education practices that supported mental health at school. In general, either the $3^{r d}$ or $5^{\text {th }}$ grade students determined that their school had implemented a positive education with a very high percentage. This means that the school has been managed in accordance with the principles of positive education which in this study is viewed with the PROSPER model. This high appraisal of the positive education implemented in that school shows that the school had enforced a variety of programs and school activities that had led to the mental health formation of the students or school community members.

\subsection{Discussion}

\subsubsection{Effort to increase positivity}

Based on the data, the efforts to increase positivity among students, among others, were in the form of giving students more freedom to think and to give opinions, building their motivation, as well as conducting outbound, swimming, hajj (Islamic Pilgrimage) ritual, and extracurricular activities (e.g. qira'ah [Quran recitation], hadroh [a form of Islamic music], dance, badminton, chess, pencak silat [Indonesian martial arts]). To cultivate 
positive thinking among students in everyday life, principals and teachers used the lecture and advice method based on Islamic religious values.

To cultivate positive thinking among students, teachers related the subject matter with daily life and related the lesson with positive values rooted in religious knowledge (e.g. hadith). As an effort to form a positive character among students, schools conducted activities such as Dhuha [forenoon] prayer, takziyah [mourning] prayer, scouting, and flag ceremonies. Furthermore, rewards and punishments were also applied. Had emotional issues occured among students, teachers helped them build more positive emotion by approaching, guiding, and advising them.

\subsubsection{Supporting students to develop social skills and underlying prosocial values and building positive relationships within the school environment}

To achieve a school that was physically and psychologically secure, there were several things that the school did. Physically, teachers and principals tried to keep students under control until all of them went home from school. Psychically, schools tried to create a fun learning environment. A fun atmosphere in the classroom will make children feel safe. In addition, schools also held programs involving parents such as mujahaddah (joint dhikr), qurbani (the sacrifice of a livestock animal), school budgeting, recitation, and donation.

Schools taught social skills and prosocial values to students by means of lectures, advice, and concrete steps in the form of behavioral examples. Special training to develop students' social skills had not been initiated. Meanwhile, the sense of togetherness in the students was cultivated through congregational Zuhr prayer and having meals together. Special programs involving the surrounding community were conducted with activities such as distributing the qurbani meat to the surrounding community or inviting community leaders to give a speech during Islamic holidays.

\subsubsection{Facilitating outcomes}

Students were encouraged to improve their achievements by teaching them how to solve daily problems through problem-solving learning method. Prophet stories were used to model children how to make good decisions. To improve the students' skills, various extracurricular activities such as qira'ah (Quran recitation), hadroh (a form of Islamic music), dance, badminton, chess, and pencak silat (Indonesian martial arts) 
were held. Those extracurricular activities were chosen because they suited the needs of the students (based on the questionnaire analysis). In addition, those activities were also similar to those in the Inter-madrassa Olympiad and the usual branches contested in school competitions (looking at available opportunities and tailoring them to their needs).

\subsubsection{Introduction, development, and application of potentials (Strengths)}

The students' talents and interests were developed through extracurricular activities and coaching activities prior to the competition. The teachers taught them how to think more deeply by using cause-and-effect questions especially in Mathematics and Natural Science subjects. Outside the classroom, the students were also taught how to think deeply. For example, when a student had a fight with another student, the teacher later invited them to think about the cause and effect of their actions. There were also some school programs that encouraged the spirituality of the students such as practicing hajj manasik, takziyah, dhuha prayer, and zuhr prayer in congregation.

\subsubsection{Raising awareness of the purpose}

Teachers provided opportunities for students to participate in group work activities organized by teachers themselves. In addition, the school conducted community service programs in the form of giving zakat al fitr (charitable contributions) to the orphanage in need of donations. Schools also provided an opportunity for students to contribute to the school by giving feedback delivered through the homeroom teachers. Students were also involved in decision-making about the learning contract, where students were actively engaged in formulating the rules. Schools facilitated students through the role of peer-mentoring or peer-supporting by means of peer-teaching method and congregational prayer activities. The role of the teacher leadership in supporting students' potential was to tell inspirational stories to enhance their motivation.

\subsubsection{Teaching resilience}

An exemplary action to teach resilience to the students was shown by the teachers through motivation enhancement during lectures. The students were taught to be brave in admitting mistakes. Rewards were given to build and develop students' courage 
in expressing and sharing their opinion. For example, a student who was able to answer a question would get money as the reward. While in teaching persistence, the teacher gave positive motivations based on Islamic values (spiritual principles). Self-management was taught through an obligation to wash their own dishes after having meals together. Independence was trained through the habituation of simple obligations, such as carrying out cleaning activities, dhuha prayer, and cleaning their dishes after meals. The key was discipline in time and in other things, so that the students could manage themselves and be independent. On the other hand, self-managementrelated training had not yet been done.

At MI Al Muhsin that focused on religious values, efforts attempted to realize the mental health program at school were done by improving the students' positive emotion, for example by granting freedom in thinking and expressing opinions, enhancing motivation through prophet and inspirational stories, conducting manasik hajj and extracurricular activities, and giving lectures and advices. To build students' positivity, the teacher often related the learning materials to the students' daily activities and to the moral values found in religion principles (e.g. hadith). Another way used by the school in building students' positive character was through the habituation of many worship activities, such as carrying out dhuha prayer, or janazah (funeral) prayer in takziyah.

School programs that involved parents in developing students' social skills and prosocial values were done through activities such as mujahaddah (congregational dhikr), qurbani, and recitation. Other than those activities mentioned earlier, the school also gave lectures, advice, and tangible actions performed as exemplary actions. As for the togetherness aspect, it was taught to the students through activities like zuhr prayer in congregation and having meals together. The school also involved the surrounding community in activities like qurbani and invited local public figures as a speaker in Islamic religious holiday celebration.

With regard to the efforts of giving the optimal learning environment and chances to learn specific skills which might improve learning outcome and achievement, the school also taught the students how to solve daily life problems through problem solving procedures. For example, storytelling (prophet stories) was to give examples to the students on how to make a good decision. The goal of extracurricular and counseling activities was to develop students' skills. The teacher also actively engaged students to think about causalities in many cases and supported spirituality by carrying out congregational zuhr prayer, takziyah, dhuha prayer, and janazah prayer.

In order to support the development of students' awareness of the purpose and meaning, the teacher gave opportunities to the students to participate in group tasks 
and discussions. In addition, the students were involved in the process of structuring their learning contract, where they actively expressed their opinion while making the contract. The school also facilitated the students' learning through peer teaching.

In teaching resilience (flexibility), teachers were to provide motivation through lectures. The students were taught to dare to admit mistakes. To grow their courage, rewards were usually given to encourage their assertiveness. While in teaching persistence, the teacher motivated and encouraged the students based on the Islamic (spiritual) values. Self-management was taught through school rules by requiring the students to come at 6.30 a.m. and wash dishes after meals. Meanwhile, to develop the students' independence character, they were required to do their cleaning duty, perform dhuha prayer, and wash dishes after meals. The underpinning key principle that the school held was discipline, both in time and in other things, so that the students could be autonomous and independent.

In general, the schools have implemented positive principles through programs that lead to the optimization of the students' potential by referring to religious teachings. As carried out by MI Al Muhsin, religiosity became the foundation of any activity or program aimed at developing the students both academically and non-academically. The results of this study is in line with [51], that showed the independent contributions of religious to positive psychological functioning, suggested that believing in God is helpful for living a good, fully functioning life.

Other studies have also shown that a person who is more spiritual, more happy and satisfied also he or she is. Its because a spiritual person has a purpose and meaning of his or her life, feel connected to a broader eternal power believe in equality and has a self and other acceptance also and these things determine the happiness [52]. Spirituality makes a person more open to positive emotions and feelings. So, it could be concluded that it is important to place spirituality aspect as the central function of the student as an individual and as a part of the social environment, to make life tasks fully functional, and to support the mental health of the individual [53].

Viewed from the spectrum of intervention model for mental health problems and mental disorders [54], the majority of school activities and programs can be categorized into mental health promotion. The development of mental health is part of a spectrum that includes activities to prevent and care for the quality of mental status of an individual. School programs that have been assessed in accordance with the principles of the PROSPER model should at least be parts of general prevention against the students' hampered potential development while providing room for capacity or potential building 
in academic, non-academic, and social fields to achieve flourishing or potential growth [55].

\section{References}

[1] World Health Organization. "Mental health: new understanding, new hope." The world health report 2001, 2001.

[2] Kumari, P. Lavanya. "Influencing factors of mental health of adolescents at school level." IOSR Journal of Humanities And Social Science 5: 48-56 (2012).

[3] Cohen \& Koenig. Religion \& mental health. Encyclopedia of Applied Psychology, 3, 255- 258. (2013).

[4] World Health Organization. Promoting mental health, concepts, emerging evidence, practice (Summary Report). Geneva, Switzerland: World Health Organization, 2004.

[5] Travasso, S.M., Rajaraman, D., \& Heymann, S. A qualitative study of factors affecting mental health amongst low-income working mothers in Bangalore, India. BMC Women's Health,14(22), 1-11. doi: 10.1186/1472-6874-14-22 (2014).

[6] Lok, N., BademII, K., \& Canbaz, M. Factors affecting adolescent mental health. Journal of Depression and Anxiety, 6(4), 1-3. doi: 10.4172/2167-1044.1000283(2017).

[7] Velten, J., Lavallee, K.L., Scholten, S., Meyer, A.H., Chi Zhiang, X., Schneider, S., \& Margraf, J. Lifestyle choices and mental health: a representative population survey. BMC Psychology, 2(58), 1-11. doi: 10.1186/s40359-014-0055-y (2014).

[8] Walsh, R. Lifesyle and mental health. American Psychologist, 66(7), 579-592. doi: $10.1037 / a 0021769$ (2011).

[9] Kazem Naisi, A., Goodarzi, A.M., \& Nezhad, M.Z. Study of factors affecting mental health. Journal of Applied Sciences, 9(10), 1956-1961. doi: 10.3923/jas.2009.1956.1961 (2009).

[10] Go'mez-Pinilla, F. Brainfoods: The effect of nutrients on brain function. Nature Reviews Neuroscience, 9, 568 -578. doi:10.1038/ nrn2421 (2008).

[11] McKeown, K, \& Haase, T. The mental health of children and the factors which influence it: A study of families in ballymun (Summary Report). Dublin: Ballymun Development Group for Children and Young People (BDGCYP) (2006).

[12] Shen, Y. A meta analysis of role ambiguity and role conflict on IS professional job satisfaction. Proceeding of the 38th Hawaii International Conference on System Sciences, January 03-06, Washington DC, USA. pp: 263.2-263.3 (2005). 
[13] Acker, G.M. The effect of organizational conditions (role conflict, role ambiguity, opportunities and social support) on job satisfaction and intention to leave among social workers in mental health care. Community Ment. Health J, 40, 322-336 (2004).

[14] Baba, V.V., Galperin, B.L., \& Lituchy, T.R. Occupational mental health: a study workrelated depression among nurses in the Caribbean. J. Nurs. Stud, 2, 163-169 (1999).

[15] Hahn, R.A., \& Truman, B.I. Education improves public health and promotes health equity. Int J Health Serv, 45(4), 657-678. doi: 10.1177/0020731415585986 (2015).

[16] Shaw, S.R., Gomes, P., Polotskaia, A., \& Jankowska, A.M. The relationship between student health and academic performance: implications for school pyschologist. School Psychologist International, 36(2), 115-134. doi: 10.1177/0143034314565425 (2015).

[17] Roberts, C.K., Freed, B., \& McCarthy, W.J. Low aerobic fitness and obesity are associated with lower standardized test scores in children. The Journal of Pediatrics, 156, 711-718. doi: 10.1016/j.jpeds.2009.11.039 (2010).

[18] Higgins, C., Lavin, T., \& Metcalfe, O. Health impacts of education: a review. Dublin: The Institute of Public Health in Ireland, 2008.

[19] Mackenbach, J. P., Stirbu, I., Roskam, A. J., Schaap, M. M., Menvielle, G., Leinsalu, M., \& Kunst, A. E. Socioeconomic inequalities in health in 22 European countries. New England Journal of Medicine, 358, 2468-2481. doi: 10.1056/NEJMsa0707519 (2008).

[20] Sigfúsdo'ttir, I.D., Kristja'ansson, Á. L., \& Allegrante, J.P. Health behavior and academic achievement in Icelandic school children. Health Education Research, 22, 70-80 (2007).

[21] Kunst, A. E., Bos, V., Lahelma, E., Bartley, M., Lissau, I., Regidor, E. Mielck, A., Cardano, M., Dalstra, J.A.A., Helmert, J.J.M.G.U., Lennartsson, C., Ramm, J., Spadea, T., Stronegger, W.J., \& Mackenbach, J. P. Trends in socioeconomic inequalities in selfassessed health in 10 European countries. International Journal of Epidemiology, 34(2), 295-305. doi: 10.1093/ije/dyh342 (2005).

[22] Taras, H., \& Potts-Datema, W. Obesity and student performance at school. Journal of School Health, 75, 291-295 (2005).

[23] Adler, N. E., \& Newman, K. Socioeconomic disparities in health: pathways and policies. Health Affairs, 21(2), 60-76 (2002).

[24] Marmot, M., Allen, J., Bell, R., Bloomer, E., \& Goldblatt, P.,. WHO European review of social determinants of health and the health divide. The Lancet, 380(9846), 10111029. doi: 10.1016/S0140-6736(12)61228-8 (2012). 
[25] Telford, R.D., Cunningham, R.B., Fitzgerald, R., Olive, L.S., Prosser, L., Jiang, X., \& Telford, R.M. Physical education, obesity, and academic achievement: A 2-year longitudinal investigation of Australian elementary school children. American Journal of Public Health, 102, 368-374. doi: 10.2105/AJPH.2011.300220 (2012).

[26] World Health Organization. Atlas: Child and adolescent mental health resources. Geneva, Switzerland: World Health Organization, 2005.

[27] Glennie, E.J., Rosen, J.A., Snyder, R., Woods-Murphy, M., \& Bassett, K. Student social and emotional development and accountability: Perspective of teachers. Arlington, VA: National Network of State Teachers Of the Year (NNSTOY), 2017.

[28] Cristovao, A.M., Candeias, A.A., \& Verdasca, J. Social and emotional learning and academic achievement in Portuguese schools: A bibliometric study. Front. Psychol, 8(1913), 1-12. doi: 10.3389/fpsyg.2017.01913 (2017).

[29] Barry, M.M., \& Dowling, K. A Review of the Evidence on Enhancing Psychosocial Skills Development in Children and Young People. HPRC, National University of Ireland, Galway. doi: 10.13025/S8001V (2015).

[30] Miyamoto, K., Huerta, M.C., \& Kubacka, K. Fostering social and emotional skills for well-being and social progress. European Journal of Education, 50(2), 147-159. doi: 10.1111/ejed.12118 (2015).

[31] Zins, J. E., Weissberg, R. P., Wang, M. C., \& Walberg, H. J. (Eds.). Building academic success on social and emotional learning: What does the research say? New York: Teachers College Press, 2004.

[32] RI, K. K. Report of Primary Health Research (Riset Kesehatan Dasar) 2013. Jakarta: Ministry of Health of the Republic Indonesia, 2013.

[33] Seligman, M., \& Csikszentmihalyi, M. Positive psychology: An introduction. American Psychologist, 55, 5-14 (2000).

[34] Meyers, M.C., van Woerkom, M., \& Bakker, A.B. The added value of the positive: A literature review of positive psychology interventions in organizations. European Journal of Work and Organizational Psychology, 22(5), 618-632. doi: 10.1080/1359432X.2012.6 (2013).

[35] Farbstein, I., Mansbach-Kleinfeld, I., Levinson, D., Goodman, R., Levav, I., Vograft, I., Kanaaneh, R., Ponizovsky, A.M., Brent, D.A., \& Apter, A. Prevalence and correlates of mental disorders in Israeli adolescents: Results from a national mental health survey. Journal of Child Psychology and Psychiatry, 51(5), 630-639. doi:10.1111/j.14697610.2009.02188.x. (2010).

[36] Costello, E.J., Mustillo, S., Keller, G., \& Angold, A. Prevalence of psychiatric disorders in childhood and adolescence. In B.L. Levin, J. Petrila, \& K.D. Hennessy (Eds.), Mental 
health services: A public health perspective (pp. 111-128). Oxford: Oxford University Press (2004).

[37] Sheldon, K.M., \& King, L. Why positive psychology is necessary. American psychologist, 56(3), 216 (2001).

[38] Gable, S.L., \& Haidt, J. What (and why) is positive psychology?. Review of general psychology, 9(2), 103. doi: 10.1037/1089-2680.9.2.103 (2005).

[39] Dulagil, A., Green, S., \& Ahern, M. Evidence-based coaching to enhance senior students' wellbeing and academic striving. International Journal of Wellbeing, 6(3), 131-149. doi:10.5502/ijw.v6i3.6 (2016).

[40] Shankland, R., \& Rosset, E. Review of Brief School-Based Positive Psychological Interventions: a Taster for Teachers and Educators. Educ Psychol Rev, 29(2), 363392. doi: 10.1007/s10648-016-9357-3 (2017).

[41] Morrison, W., \& Kirby, P. Schools as a setting for promoting positive mental health: better practices and perspectives. Summerside, PEI: The Joint Consortium for School Health; 2010 (2012).

[42] Noble, T., \& McGrath, H. The Prosper Framework for Student Wellbeing. In The PROSPER School Pathways for Student Wellbeing (pp. 25-95). Springer International Publishing (2016).

[43] Noble, T., \& McGrath, H. The PROSPER School Pathways for Student Wellbeing: Policy and Practices. Springer (2015).

[44] Adler, A. Positive education: Educating for academic succes and for a fulfilling. Psychologist Papers, 38(1), 50-57. doi: 10.23923/pap.psicol2017.2821 (2017).

[45] Bas, A.U., \& Firat, N.S. The Views and Opinions of School Principals and Teachers on Positive Education. Journal of Education and Training Studies, 5(2), 85-92 (2017).

[46] Govindji, R., \& Linley, P.A. Strengths use, self-concordance and well-being: Implications for strengths coaching and coaching psychologists. International Coaching Psychology Review, 2, 143-153 (2007).

[47] Fredericks, J.A., Blumenfeld, P.C., \& Paris, A.H. School engagement: Potential of the concept, state of the evidence. Review of Educational Research, 74(1), 59-109 (2004).

[48] McGrath, H., \& Noble, T. HITS and HOTS: Teaching + thinking + social skills. Pearson Education: Melbourne (2010).

[49] McGrath, H. \& Noble, T. BOUNCE BACK! A wellbeing and resilience program (lower primary k-2; middle primary: yrs 3-4; upper primary/junior secondary: yrs 5-8). Melbourne: Pearson Education (2011). 
[50] Agarwal, S., \& Mishra, P.C. Strategies to enhance student well-being in a school environment. Remarking an Analisation, 2(4), 158-164 (2017).

[51] Aghababaei, N. Scientific faith and positive psychological functioning. Mental health, religion \& culture, 19, 734-741. doi: 10.1080/13674676.2016.1256383 (2017).

[52] Sharma, S.K., \& Sharma, O.P. Spirituality leads to happiness: A correlative study. The International Journal of Indian Psychology, 3(2), 50-54 (2016).

[53] Myers, J. E., \& Sweeney, T. J. (Eds.). Counseling for wellness: Theory, research, and practice. Amer Counseling Assn, 2005.

[54] Mahoney, J.L., Larson, R., Eccles, J.S., \& Lord, H. Organized activities as developmental contexts for children and adolescents. In J.L. Mahoney, R. Larson \& J.S. Eccles (Eds.), Organized Activities as Contexts of Development: Extracurricular Activities, After-School and Community Programs (pp. 3-22). Mahwah, New Jersey: Erlbaum (2005).

[55] Keyes, C.L. Human flourishing and salutogenetics. Genetics of psychological wellbeing: The role of heritability and genetics in positive psychology, 3-19. (2015). 